\title{
Cognitive Effects of Interactive Public Display Applications
}

\author{
Florian Alt, Stefan Schneegass, Michael Girgis, Albrecht Schmidt \\ Institute for Visualization and Interactive Systems(VIS) \\ University of Stuttgart \\ Pfaffenwaldwing 5a, 70569 Stuttgart, Germany \\ \{florian.alt, stefan.schneegass, albrecht.schmidt\}@vis.uni-stuttgart.de
}

\begin{abstract}
Many public displays are nowadays equipped with different types of sensors. Such displays allow engaging and persistent user experiences to be created, e.g., in the form of gesture-controlled games or content exploration using direct touch at the display. However, as digital displays replace traditional posters and billboards, display owners are reluctant to deploy interactive content, but rather adapt traditional, non-interactive content. The main reason is, that the benefit of such interactive deployments is not obvious. Our hypothesis is that interactivity has a cognitive effect on users and therefore increases the ability to remember what they have seen on the screen - which is beneficial both for the display owner and the user. In this paper we systematically investigate the impact of interactive content on public displays on the users' cognition in different situations. Our findings indicate that overall memorability is positively affected as users interact. Based on these findings we discuss design implications for interactive public displays.
\end{abstract}

\section{Keywords}

Public Display, Digital Signage, Interactivity, Recall, Recognition

\section{Categories and Subject Descriptors}

H.5.1 [Multimedia Information Systems]: Evaluation / Methodology.; H.5.2 [User interfaces]: Interaction styles

\section{INTRODUCTION}

Commercial public displays have become an essential part of the urban landscape. They are widely deployed by large outdoor advertisers and increasingly by smaller retailers, restaurants, bars, and public institutions. The main drivers for setting up public displays are advertising (e.g., in airports, railway stations, and high streets), digital signage solutions (e.g., in public buildings), and making locations more attractive to users (e.g., screens in bars and cafes).

Much of the content currently shown on these displays is not specifically designed for public displays but for other media, such as traditional billboards or television. Hence, it does not cater well to the properties of digital public displays and most importantly,

Permission to make digital or hard copies of part or all of this work for personal or classroom use is granted without fee provided that copies are not made or distributed for profit or commercial advantage and that copies bear this notice and the full citation on the first page. Copyrights for components of this work owned by others than ACM must be honored. Abstracting with credit is permitted. To copy otherwise, to republish, to post on servers or to redistribute to lists, requires prior specific permission and/or a fee.

PerDis '13, June 04 - 05 2013, Mountain View, CA, USA Copyright 2013 ACM 978-1-4503-2096-2/13/06...\$15.00.

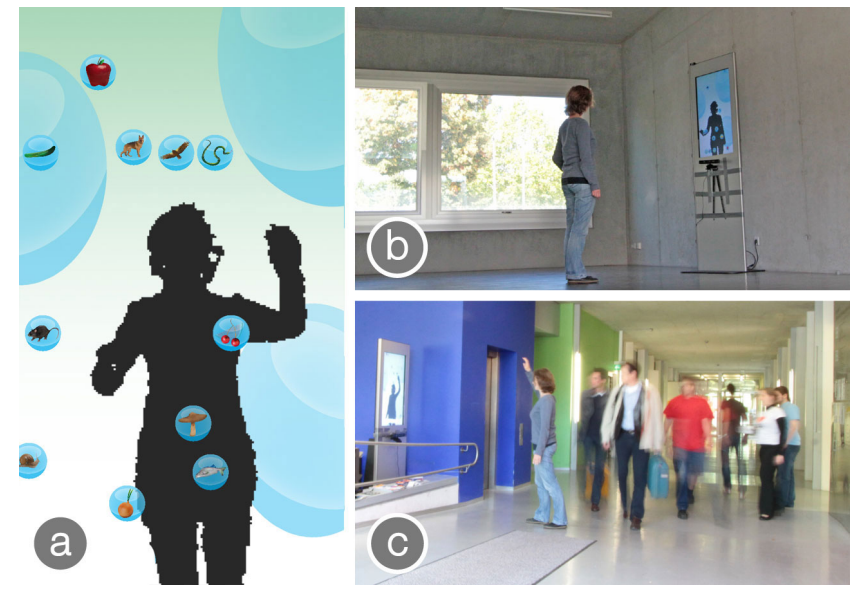

Figure 1: Study setup: We evaluated memorability of interactive content on public displays. To assess the influence of different situations, we deployed an interactive soap bubble game (a) in a waiting situation (b) and in a passing-by situation (c).

the rather short interaction times. Passersby arrive in the middle of the spot, don't even understand what it is about, and leave before the punchline. Owners of public displays have partially recognized the problem and are increasingly creating suitable content consisting of small chunks of information that are displayed in a time-multiplexed way. For example, displays in subway stations show news content, followed by the weather forecast, and short cartoons. Content is occasionally interlaced with (contextual) advertisements. This undoubtedly makes public displays more attractive to passersby, but still does not exploit the full capabilities of interactive displays that actively engage the user [1]. Devices such as the Microsoft Kinect or touch-enabled displays allow interactive applications to be deployed. At the same time, models of human cognition suggest that interactivity has the potential to increases the user experience. Examples exists today, where display owners are experimenting with such applications, but the majority of outdoor display owners are still reluctant to deploy interactive displays.

In this paper we argue that the value of public displays can be increased by using interactive content - both for the viewer and for the owner. Compared to non-interactive displays, we believe that people can remember content shown on interactive public displays better. In an experiment, we investigate how interactivity impacts memorability for different content and in different situations (Figure 1). Increasing the users' ability to remember content from a public screen is particularly valuable for advertising, but also has clear implications on digital signage solutions and information displays in general. The results from our experiment show that interac- 
tive public display applications have a positive influence on recognition. Furthermore, we found evidence that the situation (waiting vs. passing-by) does not significantly impact memorability.

The contribution of this paper is threefold. First, we present a design space for interactive public display applications identifying dimensions that help to classify, compare, assess, and discuss such applications. Second, we present findings from an experiment investigating memorability by measuring recall and recognition. Third, we present implications for designing effective interactive displays.

\section{BACKGROUND AND RELATED WORK}

As public displays become more prominent we are interested in cognitive effects on the user. Prior work on different media types e..g, interactive TV [11], websites [17], and online catalogues [20] - indicates that interactivity of content is a candidate for affecting cognition. The results are specific for these media types and cannot be applied to public displays. Still, they inspired us to investigate the impact of interactivity on cognition on public displays.

\subsection{Understanding Cognitive Effects}

One of the most general paradigm in psychology concerning cognitive effects is the Stimulus-Organism-Response paradigm [3, 23]. In contrast to the classic Stimulus-Response paradigm that considers cognitive processes as a 'Black Box', the neo-behavioral S-O-R paradigm considers hypothetic constructs such as involvement and emotions as intervening variables [22]. We are particularly interested in involvement, which can be achieved during three phases: attention, comprehension, and elaboration [9]. We assume that attention is given as soon as the user interacts. Elaboration can only be measured in the long-term based on user actions and is therefore out of the scope of this study. Hence, we focus on comprehension and draw upon recall and recognition as widely accepted measure to quantify involvement. We see these two measures as suitable means to assess involvement and thus cognitive effect on users.

\subsection{Impact of Interactivity}

Researchers investigated the general impact of interactivity. Cho et al. [6] and $\mathrm{Wu}$ [24] found that interactivity has a positive impact on user attitudes whereas no influence on user satisfaction can be attributed [21]. Risden et al. showed that interactive Web games are more likely to increase brand awareness compared to watching an ad for the same brand on TV [18]. Also exposure (i.e., the number of times an event was experienced) did not have an influence.

Bezjian-Avery et al. [5] compared interactive and traditional forms of advertising based on the dimensions 'presentation of the message', the 'personality characteristics of the user', and the 'nature of the message'. Liu identified three dimensions of interactivity on web sites: active control, two-way communication, and synchronicity [12]. For studying public displays and to allow abstraction from specific application we focus on active control. Rodgers and Thorson distinguish a serious and a playful mode [19]. Based on their findings they presented a model for the Internet [19]. Our study draws on the playful aspects as we are interested in public settings and voluntary interaction which is curiosity-driven or to pass time.

\subsection{Summary}

The impact of interactivity on cognition in the domain of public displays has not been explored so far. However, the results of previous investigations indicate that this is a challenging task. There are a number of aspects that have a potential influence. Hence, we believe it to be crucial to identify and analyze the results with regard to these aspects. As a consequence, we first identify dimensions that form a design space for interactive display applications.

\section{DESIGN SPACE}

This paper focuses on public displays as toys [14] - more specifically, on interactive public display applications, that enable interaction with objects on the screen in a playful manner. We expect such applications to be suitable for displays deployed along trajectories of passersby and particularly in waiting situations, e.g., at bus stops. We assume that interaction with objects on public displays has an effect on recall and recognition. Being able to show such an effect would provide a rationale for display providers to deploy more interactive applications and hence make displays more attractive.

Our design space is based upon an extensive review of work on interactive public displays, including papers (cf. [2]), videos, and project websites. Based on a careful analysis of the material we extracted a set of dimensions that potentially affect cognition, discussed each of the dimensions, and identified relevant values. Table 1 summarizes and describes the different dimensions' values.

\subsection{User Situation}

People encounter public displays in very different situations, e.g., while waiting, while being on-the-go, while eating, or during shopping. In weak occupation situations, people usually have more time to engage as compared to strong occupation situations, such as while en route to work.

With particular interest to this dimension is Hyde and Jenkins' finding that in incidental learning experiments the user's intention to learn, does not have a significant influence on the learning success [10]. In contrast, the way information is being processed, determines how much information can be memorized. From this, it can be concluded that the mental performance stays the same as long as the same mental activities are performed throughout the duration of learning. This suggests that the situation in which a user encounters a public display may not have an influence on cognition.

We discussed whether it would be sufficient to simply consider the interaction time with the display. Yet, further aspects, such as stress or cognitive load, may have an influence. Hence, we suggest a continuum between weak and strong occupation situations.

\subsection{Interactivity of Content}

We found that scenes on public display often contain many different objects, of which some are interactive and others not. We expect a difference in recall and recognition, depending on whether an object can be manipulated or not. Hence, three cases are distinguished: (1) the screen contains only non-interactive content (e.g., a current, non-interactive advertising displays), (2) the screen contains interactive and non-interactive content (e.g., interactive foreground, static background), or (3) all objects are interactive.

\subsection{Interaction Type}

The technology deployed usually determines the type of interaction. Whereas touch-enabled screens enable direct interaction (i.e., dragging/dropping an object), mid-air gestures are indirect and require a mapping to the feedback on the screen. Thus, the expressiveness can be controlled, e.g., by implementing a transfer function that requires the user to move more or less in front of the screen.

\subsection{Integrating Content and Message}

We identified three ways a message can be placed within an application [1]. Messages could be shown exclusively (i.e., no other content), with other content on the same screen but separated, or they could be integrated with other content. We believe that additional content could indeed influence cognition. Prior work shows that people remember content around interesting magazine articles less than content around less interesting articles [16]. 


\begin{tabular}{|c|c|c|}
\hline & пा & Values \\
\hline \multirow{2}{*}{ 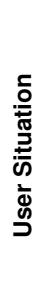 } & Weak occupation & $\begin{array}{l}\text { In these situations, people are open to } \\
\text { perceive the content of displays, are relaxed, } \\
\text { and are more likely to be taken in. Examples } \\
\text { include waiting situations at bus/train stations, } \\
\text { next to the coffee maker, or the copy machine. }\end{array}$ \\
\hline & Strong occupation & $\begin{array}{l}\text { In many situations where people encounter } \\
\text { public displays, they are in a hurry and are on } \\
\text { a schedule. Generally, this leads to shorter } \\
\text { interaction times and content usually needs to } \\
\text { be specifically designed for such situations. }\end{array}$ \\
\hline \multirow{3}{*}{ 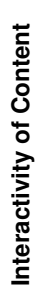 } & $\begin{array}{r}\text { Non-interactive } \\
\text { Content Only }\end{array}$ & $\begin{array}{l}\text { Non-interactive content does not enable } \\
\text { interaction but constitutes a static, constantly } \\
\text { visible part of the application. }\end{array}$ \\
\hline & Mixed Content & $\begin{array}{l}\text { Particularly for complex scenes, applications } \\
\text { may consist to varying degrees of interactive } \\
\text { and non- interactive objects. }\end{array}$ \\
\hline & $\begin{array}{r}\text { Interactive Content } \\
\text { Only }\end{array}$ & $\begin{array}{l}\text { In applications with only interactive content, } \\
\text { users can interact with any object shown in } \\
\text { the application. }\end{array}$ \\
\hline \multirow{2}{*}{ 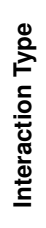 } & Direct Interaction & $\begin{array}{l}\text { Direct interaction describes techniques where } \\
\text { users directly control the object they are } \\
\text { interacting with (e.g., touchscreen). }\end{array}$ \\
\hline & Indirect Interaction & $\begin{array}{l}\text { Indirect interaction refers to techniques that } \\
\text { involve sensors and processing to translate } \\
\text { the user's motion into a representation on the } \\
\text { screen (e.g., Kinect, mobile phone). }\end{array}$ \\
\hline \multirow{3}{*}{ 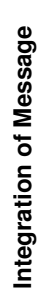 } & Message only & $\begin{array}{l}\text { In the simplest case, users are only } \\
\text { interacting with the message, e.g., the latest } \\
\text { Nike basketball. }\end{array}$ \\
\hline & $\begin{array}{r}\text { Message \& } \\
\text { Content } \\
\text { (Separated) } \\
\end{array}$ & $\begin{array}{l}\text { A scene can contain further content apart } \\
\text { from the message, e.g., static background } \\
\text { and Nike basketball. }\end{array}$ \\
\hline & $\begin{array}{r}\text { Message \& } \\
\text { Content } \\
\text { (Integrated) }\end{array}$ & $\begin{array}{l}\text { making the distinction not obvious } \\
\text { e.g., a brand logo on the interactive }\end{array}$ \\
\hline \multirow{2}{*}{ 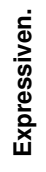 } & $\begin{array}{r}\text { Low } \\
\text { Expressiveness } \\
\end{array}$ & $\begin{array}{l}\text { People only interact with their hands and do } \\
\text { not make expressive movements (e.g., touch). }\end{array}$ \\
\hline & $\begin{array}{r}\text { High } \\
\text { Expressiveness }\end{array}$ & $\begin{array}{l}\text { People make whole body gestures and move } \\
\text { in front of the displays as they interact (e.g., } \\
\text { gestures) }\end{array}$ \\
\hline \multirow{2}{*}{ 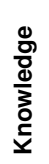 } & Prior Knowledge & $\begin{array}{l}\text { The message shown on the display is not new } \\
\text { to the user (e.g., an ad they have seen } \\
\text { before). }\end{array}$ \\
\hline & $\begin{array}{r}\text { No Prior } \\
\text { Knowledge }\end{array}$ & $\begin{array}{l}\text { The user does not know the message (brand } \\
\text { or product) a priori. }\end{array}$ \\
\hline
\end{tabular}

Table 1: Design space for interactive public display apps.

\subsection{Expressiveness of Interaction}

Various interaction techniques with a potential influence on cognition exist. These include touch, gestures, presence, etc. A comprehensive overview can be found in Müller et al. [14]. Different interaction techniques require different levels of expressiveness e.g., applications using the presence of the passerby require less expressive movements (low expressiveness) compared to a game using whole body movements (high expressiveness).

\subsection{Prior Knowledge of the Message}

We believe the user's knowledge about a message to have a strong influence on cognition. For example, if a user knows the brand advertised, this might positively affect whether or not they can remember the message. Hence, we distinguish between prior knowledge and no prior knowledge of the message.

\section{HYPOTHESES}

We aim at answering the following hypotheses with the experiment presented in the remainder of this paper.

H1. Interaction influences cognition by increasing the involvement. We expect that, in general, people are more involved in interactive public display applications, which is measured by assessing recall and recognition.

H2. The type of situation when passersby encounter public displays has an influence on cognition. As we discussed earlier, we expect that the situation in which users interact affect cognition and the effects are higher in a waiting situation. This is done by assessing recall and recognition as well.

\section{APPARATUS}

In order to test our hypotheses we developed an easy, interactive 'soap bubble game'. The game requires players to pop soap bubbles floating across the screen with their hands. As a player pops a bubble, it vanishes from the screen and the content in the bubble drops to the ground and disappears. The game was implemented in C\# and uses the Kinect SDK in order to track gestures from the user standing in front of the display. We implemented the game in a way such that it is possible to use either touch at the display or the Kinect to pop the bubbles. In order to avoid bubbles being popped accidentally as people pass through the visual field of the Kinect, bubbles can only be destroyed using the hands. In order to integrate content, the game allows arbitrary objects to be embedded either in the background or into the semi-transparent bubbles (see Figure 1a). As we intended to deploy the game in an in-thewild setting, attracting and communicating interactivity is crucial. According to Müller et al. [15], we drew upon the user's silhouette.

The soap bubble game granted considerable artistic freedom with regard to the dimensions presented earlier in this paper:

- Interactivity of Content: Soap bubbles can be interactive (users can pop them) or non-interactive.

- Interaction Type and Expressiveness: The game supports direct interaction (touch, low expressiveness) and non-direct interaction (body gestures, high expressiveness).

- Integrating the Message and Knowledge: Arbitrary messages can be displayed in the background of the application or be integrated with the soap bubbles.

- User Situation: The game supports different situations by providing mechanisms that attract people both in weak (waiting) and high (passingly) occupation settings.

We designed the game to run on a 42" portrait-mode eKiosk display. The software runs on a laptop, which also stores the depth video from the Kinect and an interaction log. The Kinect was attached to the front of the display in all conditions. Apart from the Kinect, no interactivity cues, such as a call-to-action, were provided.

Gerrig et al. [8] show that almost everything can be used as a retrieval cue - scent, colors, words, persons, images, or even brand logos. We decided to use images of animals and fruits for the messages shown in the bubbles (Figure 1c) to ensure that every participant is familiar with all content items shown on the display. For the background, we use an artistic image of a super-sized soap bubble that could clearly be identified as non-interactive object. A professional designer created the background image, the soap bubbles, the fruits, and the animals. 
Miller et al. show that humans can store $7+/-2$ chunks of information leading to that only 5-9 items can be retrieved shortly after presentation [13]. Hence, we use 24 items (12 fruits and 12 animals) to exhaust the capacity of the human short-term memory. To make sure that a participant has the chance to see each item, all items are shown at the same time. As soon as a bubble with an item is popped, it floats again onto the screen.

\section{EXPERIMENT}

We used the soap bubble game in an experiment to evaluate the impact of interactivity with regard to the different dimensions. In total we observed and collected questionnaires from 62 participant (18 female) aged between 18 and 37 years $(M=23.859, S D=$ 3.517). All of them were naive to our hypotheses and did not know that they were being observed while interacting with our system.

\subsection{Scope}

We are primarily interested in the impact of interactivity on cognition (H1). We also look at the impact of the user situation (H2), comparing a waiting situation as an example for low occupancy against a passing by situation (high occupancy). Further dimensions are left for future work.

\subsection{Metrics}

To understand the impact on memorability, we opted to measure recall and recognition in the short term. So-called free recall tests require users to freely reproduce items that have been previously presented. The test measures, how much a participant can spontaneously remember. Recognition tests present users a selection of items and requires them to select those that have been part of the previous presentation [8]. Previous research shows that the results of a memory task strongly depend on encoding this information while learning. Hence, it is was absolutely crucial that participants were not aware of that they took part in a test [10].

Recall and recognition were assessed using questionnaires. All participants were asked to write down any item they remembered to have been shown in the soap bubbles (recall). After that we showed them a list of 48 items, 24 of which were actually shown on the screen (recognition) and let them rate on a 5-Point Likert scale how sure they were that they had seen them on the display (1=I definitely did not see the item, 5=I definitely saw the item).

During the data analysis, we calculated a 'recognition score' for each participant by summing up the single Likert scale ratings for each item shown on the display and subtracting the items that were not shown at all. The sum ranges from -96 to 96 points - higher scores indicate that participants recognized items better.

\subsection{Low Occupancy (Waiting)}

In order to create waiting situations, we prepared a hallway in our lab with a public display running the soap bubble game for two weeks (see Figure 1b). The hall did not contain any furniture.

In this first part of the experiment we focused on the overall impact of interactivity. The display showed two conditions: (1) an interactive condition using body gestures, and (2) a non-interactive baseline condition. For the interactive condition, we used the Kinect to enable body gestures. For the non-interactive condition we used a screen-capture video of a researcher playing the game.

\subsubsection{Participants and Procedure}

We recruited participants from another (non-display) study that ran in parallel at our lab. In this part of the experiment, 37 participants (15 female), aged between 18 and $29(M=23.216$, $S D=2.983$ ) took part.
As the participants arrived, a researcher led them to the hallway with the display and told them that the room for the study was still being prepared and that another researcher would be with them in two minutes. After that, we left them alone in the hallway for exactly five minutes. We neither told them to interact with or look at the display, nor was any interactivity clue provided apart from the Kinect and the silhouette representation. After five minutes, a second researcher joined the participant and led them to one of the meeting rooms ${ }^{1}$. There, we asked them whether they would be happy to fill in a questionnaire on the public display they just saw or interacted with in the hallway. We explained that this was part of an experiment we are conducting, that they would be remunerated with 5 euros for participating, and that they could abort participating at any time. After they filled in the questionnaire, we briefed them and explained them the purpose of the study. Finally, we led them to the experiment they initially arrived for.

\subsection{High Occupancy (Passing By)}

In the second part of the experiment, we investigated passing by situations. We deployed the public display at the ground level of a university building for two weeks. It was placed next to the main entrance with lots of traffic (see Figure 1c). Due to the public space, it was not possible to record a video of the participants for a posthoc analysis. Hence, we observed the participants from a hidden location and recorded the (privacy-preserving) Kinect depth video.

\subsubsection{Participants and Procedure}

As in the waiting situation we used a silhouette as user representation. In total, 25 passersby (11 female) aged 20 to 37 ( $M=$ $25.120, S D=3.908)$ participated in this experiment.

After they finished interacting, we approached them and asked whether they were happy with participating in a user study. Similar to the waiting situation, we told them that they would be remunerated and that they could abort participating in the study at any time. Again, they had to fill out a questionnaire and were debriefed.

\section{RESULTS}

In order to analyze the data of the experiment we assessed the data from the questionnaires. We looked at how many items were correctly recalled. For recognition we calculated the recognition score for each participant.

\subsection{Overall Effect of Interactivity}

First, we were interested in the overall effects of interactivity (H1). Thus, we compare recall and recognition in the non-interactive baseline condition with the interactive condition in the waiting situation. From the 37 participants (17 interactive, 20 non-interactive), we had to exclude the data of 5 participants who did not interact in the interactive condition. In the interactive condition, participants remember on average 4.867 items $(S D=2.295)$, whereas they remember only 3.118 items $(S D=2.118)$ in the non-interactive condition (see Figure 2 - left). An independent measures $t$ test shows that the difference in the number of remembered items (recall) is statistically significant, $t(30)=-2.242, p<.05, r=.375$.

We calculated the scores from the recognition results. In the interactive condition, participants score on average .730 points $(S D=$ $.437)$ and in the non-interactive condition .840 points $(S D=.423)$.

\footnotetext{
${ }^{1}$ Note that we used the same meeting room for all participant during the study, as prior work has shown the context in which memory performance is tested to have an influence on the results [4]. Furthermore, we deliberately kept the retention interval short ( $<5$ minutes) as previous work showed that participants forget $40 \%$ of what they have learned within the first 20 minutes, and $77 \%$ after the first 6 days (forgetting curve) [7].
} 

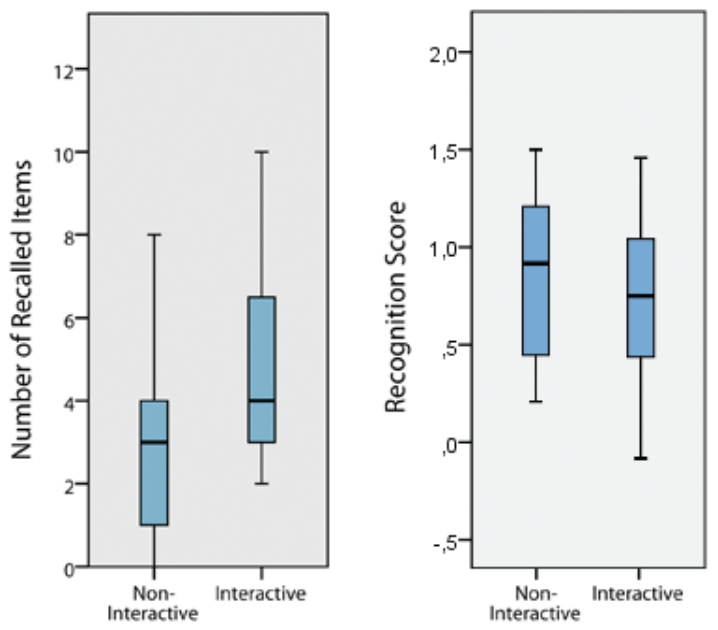

Effect of Interactivity

Figure 2: Boxplots of recall (left) and recognition (right) for the effect of interactivity. Participants can recall statistical significantly more items in the interactive than in the non-interactive condition. The difference in recognition is not statistically significant.

Despite the differences in the means (Figure $2-$ right), the $t$ test shows no significance, $t(30)=.719, p=.478, r=.130$.

With regard to these results, we can accept $\mathrm{H} 1$ - there is strong evidence that interaction based on body gestures has a statistically significant influence on cognition by increasing the users' ability to recall content. There is no significant effect on recognition.

\subsection{User Situation}

Second, we were interested in differences between situations (waiting vs. passing by). To obtain comparable results, we considered only the interactive condition in the waiting situation. Totally, data from 40 participants (15 waiting, 25 passing by) was analyzed.

For recall, participants in the waiting situation remembered on average 4.867 items $(S D=2.295)$ and in the passing by situation 3.680 items $(S D=2.295)$. Figure 3 depicts the results. An independent $t$ test shows no statistically significant difference, $t(38)=1.506, p=.140, r=.237$. Result from the recognition test shows no significance as well. In the waiting condition, participants scored higher in the recognition test $(M=.730, S D=$ $.437)$ than in the passing by situation $(M=.713, S D=.501)$. However, the $t$ test shows no significance, $t(37)=.108, p=.914$.

Based on our findings, we can not accept H2. The concrete situation in which users interact and thus the level of occupancy does not seem to have a significant influence on cognition. The statistical power of our test is not large enough to accept the null hypothesis.

\subsection{Qualitative Findings}

Feedback and brief interviews with the participants revealed that none of them realized that the display was under investigation before we approached them. We believe this to be a strong indicator for high internal validity [2]. At the same time we believe the results to be also ecologically valid due to the realistic situations.

During the interviews, participants showed high interest in our research question and stated that they would prefer such interactive games compared to traditional advertising on displays. They seemed to not be bothered that even interactive games could be exploited by advertisers to convey messages.
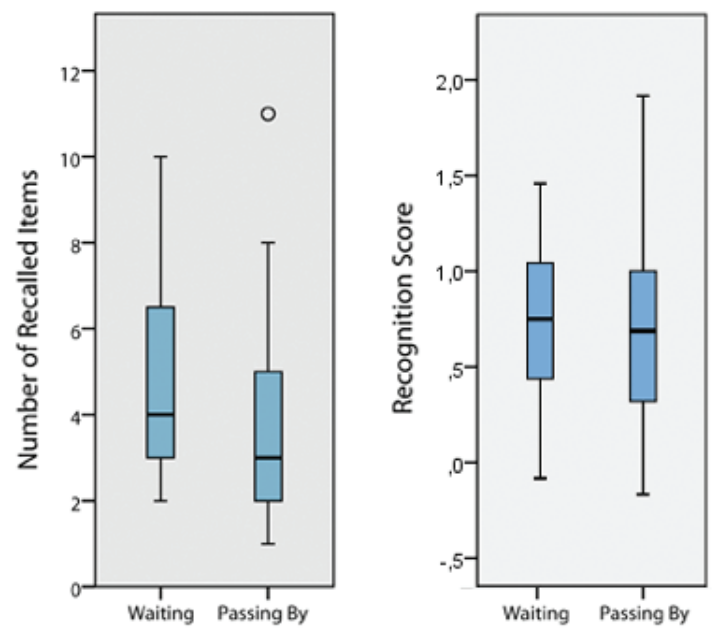

Situation

Figure 3: Boxplots of recall (left) and recognition (right) for user situations. The difference is not significant.

With regard to the interactivity clues, most participants stated to have been attracted by the Kinect and some of the popping sound. The Kinect further helped people to understand that they could interact with our game using body gestures.

\section{DISCUSSION}

Our experiment yields a number of findings we believe to be useful for the design and deployment of digital signage applications. We envision interactive public displays to increase awareness of the content, to enhance the nowadays often negative view of (advertising) displays, and to improve one of the core subjectives of public displays, that is information disseminations.

Increasing awareness of the content. Our results suggest that interactive applications are particularly valuable for creating and increasing awareness of the content. For example, a display that is used to communicate information about a tourist attraction (e.g., opening hours, prices, etc.) could hide this information behind an object that users need to touch to reveal this information, instead of simply displaying information statically. Based on our findings, users are likely to remember this information more easily. A second example is advertisers who want to increase awareness of a new brand or product. They can benefit from an application that integrates an according message and enables users to interact with it.

Fostering a positive perception of public displays. As has been shown in prior research, displays currently struggle with display blindness. Our findings suggest that interactivity has the potential to overcome this phenomenon. We found that not only a considerable percentage of people interacts, but that also their perception of the display is positively affected. People state that they are not afraid of advertisers trying to subconsciously manipulate them as they interact and there is also strong interest in our research. While we cannot yet support this expectation with empirical evidence, we believe that future applications can benefit from this finding and overcome display blindness in the longer term. 
Improving information dissemination. Our study looked at settings that employ playful interaction. The results suggest that creating interactive content may further be applied to applications and systems that focus on information dissemination. We expect that with an interactive public display, the successful information dissemination can be increased. This is partly an effect of the increased recall as reported in this paper and partly due to the fact that users interacting with the system attract further passersby (cf. the honeypot effect).

\section{LIMITATIONS}

We acknowledge the following limitations in our findings. As demonstrated through the presentation of the design space, a number of factors potentially influence cognition. Due to the complexity, we had to focus on core aspects.

First, we only investigated a playful application - hence no evidence can be provided with regard to applications with an informative focus. Second, we only used images in the study as retention cues. Prior work shows that almost anything can be used as a retention cue [8]. Yet, we did not quantitatively assess this. Third, the study was limited to a university environment. Still, we believe to have covered a diverse set of participants that are potential users of public displays - else they would not have deliberately interacted with the display. Fourth, we did not consider group interaction. As prior work found that users often interact in groups [15] we designed the game in a way, such that only the first person to arrive was able to interact. However, we plan to assess this in the future.

\section{CONCLUSION}

In this paper we investigated the impact of interactivity of public displays on recall and recognition. We presented a design space for interactive applications and identified important dimensions that have a potential cognitive influence. The findings from our experiment show that interactivity significantly increases recall. The situation, in which participants encounter the display, and thus their level of occupancy, does not have a significant influence. Despite the limitations of our experiment with regard to the tested type of application, the content, and the test environment, this suggests, that interactive applications can create and increase awareness, that information dissemination can be improved, and that there is potential for a more positive perception of public displays.

For future work, we plan to focus on further dimension and assess the influence on recall and recognition in the field. Furthermore, we consider the impact of group interaction on recall and recognition to be particularly interesting.

\section{ACKNOWLEDGEMENTS}

The research leading to these results has received funding from the European Union Seventh Framework Programme ([FP7/20072013]) under grant agreement no. 244011 and 600851. This project is furthermore partly funded from the German Research Foundation within the Cluster of Excellence in Simulation Technology (EXC 310/1) at the University of Stuttgart. We thank Florian Pfleiderer and Frank Steimle for their help during the user study.

\section{REFERENCES}

[1] Alt, F., Müller, J., and Schmidt, A. Advertising on Public Display Networks. IEEE Computer 45, 5 (2012), 50-56.

[2] Alt, F., Schneegaß, S., Schmidt, A., Müller, J., and Memarovic, N. How to Evaluate Public Displays. In Proc. of PerDis'12, ACM (New York, 2012), 171-176.
[3] Arora, R. Validation Of An S-O-R Model For Situation, Enduring, And Response Components Of Involvement. Journal of Marketing Research 19 (1982), 505-516.

[4] Baddeley, A. Human memory: Theory and practice. Psychology Pr, 1997.

[5] Bezjian-Avery, A., Calder, B., and Iacobucci, D. New media interactive advertising vs. traditional advertising. Journal of advertising research 38 (1998), 23-32.

[6] Cho, C.-H., and Leckenby, J. D. Interactivity as a measure of advertising effectiveness: Antecedents and consequences of interactivity in web advertising. In Proc. of AAA'99 (1999).

[7] Ebbinghaus, H. Über das Gedächtnis. Untersuchungen zur experimentellen Psychologie. Darmstadt: Wissenschaftliche Buchgesellschaft, 1885.

[8] Gerrig, R., and Zimbardo, P. Psychology and life. Pearson, 2002.

[9] Greenwald, A. G. Audience Involvement in Advertising: Four Levels. Journal of Consumer Research 11 (1984), 581-592.

[10] Hyde, T., and Jenkins, J. Recall for words as a function of semantic, graphic, and syntactic orienting tasks. Journal of Verbal Learning and Verbal Behavior 12, 5 (1973), 471-480.

[11] Kim, J. W., and Du, S. Design for an interactive television advertising system. In Proc. of HICSS'06, IEEE (2006).

[12] Liu, Y. Developing a scale to measure the interactivity of websites. Journal of Advertising Research (2003).

[13] Miller, G. The magical number seven, plus or minus two: Some limits on our capacity for processing information. Psychological review 101, 2 (1994), 343.

[14] Müller, J., Alt, F., Michelis, D., and Schmidt, A. Requirements and Design Space for Interactive Public Displays. In Proc. of MM'10, ACM (New York, 2010), 1285-1294.

[15] Müller, J., Walter, R., Bailly, G., Nischt, M., and Alt, F. Looking Glass: A Field Study on Noticing Interactivity of a Shop Window. In Proc. of CHI'12, ACM (New York, 2012), 297-306.

[16] Norris, C., and Colman, A. Context effects on recall and recognition of magazine advertisements. Journal of Advertising (1992), 37-46.

[17] Pavlou, P., and Stewart, D. Measuring the effects and effectiveness of interactive advertising: A research agenda. Journal of Interactive Advertising 1, 1 (2000).

[18] Risden, K., Czerwinski, M., Worley, S., Hamilton, L., Kubiniec, J., Hoffman, H., Mickel, N., and Loftus, E. Interactive advertising: patterns of use and effectiveness. In Proc. of CHI'98, ACM (New York, 1998), 219-224.

[19] Rodgers, S., and Thorson, E. The interactive advertising model: How users perceive and process online ads. Journal of Interactive Advertising 1, 1 (2000), 26-50.

[20] Schulte, F., Heineken, E., and Gall, S. What's in it for product marketing when using a pageflip in online-catalogues? $i$-com 8, 2 (2009), 40-46.

[21] Shankar, V., Smith, A., and Rangaswamy, A. Customer satisfaction and loyalty in online and offline environments. Int. Journal of Research in Marketing 20, 2 (2003), 153-175.

[22] Trommsdorff, V. Konsumentenverhalten, 7th ed. Kohlhammer, Stuttgart, 2009.

[23] Woodworth, R. Dynamics of behavior. Methuen's manuals of modern psychology. Holt, 1958.

[24] Wu, G. Perceived interactivity and attitude toward web sites. In Proc. of AAA'99 (1999), 254-262. 